\title{
The Relationship Between Gastric Myoelectric Activity and SCN5A Mutation Suggesting Sodium Channelopathy in Patients With Brugada Syndrome and Functional Dyspepsia - A Pilot Study
}

\author{
Kyo Tae Jung, ${ }^{1,3}$ Hyojin Park, ${ }^{1,3 *}$ Jie-Hyun Kim, ${ }^{1,3}$ Dong-Jik Shin, ${ }^{4}$ Bo Young Joung, ${ }^{2}$ Moon-Hyoung Lee ${ }^{2}$ and Yang Soo Jang ${ }^{2}$ \\ Divisions of ${ }^{1}$ Gastroenterology and ${ }^{2}$ Cardiology, ${ }^{3}$ Department of Internal Medicine, Gangnam Severance Hospital, Yonsei University College \\ of Medicine, Seoul, Korea; and ${ }^{4}$ Cardiovascular Genome Center, Yonsei University Medical Center, Seoul, Korea
}

\begin{abstract}
Background/Aims
SCN5A encodes the cardiac-specific Nav1.5 sodium channel, and Brugada syndrome is a cardiac conduction disorder associated with sodium channel $\alpha$-subunit (SCN5A) mutation. The SCN5A-encoded Nav1.5 channel is also found on gastrointestinal smooth muscle and interstitial cells of Cajal. We investigated the relationship between functional dyspepsia (FD) and SCN5A mutation to evaluate sodium channelopathy in FD.
\end{abstract}

\section{Methods}

Patients with Brugada syndrome or FD were examined using upper endoscopy, electrogastrography (EGG), FD symptom questionnaire based on Rome III criteria and genetic testing for SCN5A mutation. Symptom scores of FD and EGG findings were analyzed according to SCN5A mutation.

\section{Results}

A total of 17 patients (4 Brugada syndrome and $13 \mathrm{FD}$ ) participated in the study. An SCN5A mutation was noted in $75.0 \%$ of the patients with Brugada syndrome and in $1(7.7 \%)$ of the patients with FD. Of 4 patients with SCN5A mutation, $2(50 \%)$ had FD. Postprandial tachygastria and bradygastria were noted in $2(50 \%)$ and $1(25 \%)$ of the patients with SCN5A mutation, respectively. The EGG findings were not significantly different between positive and negative mutation in 17 patients.

\section{Conclusions}

Although we did not find statistically significant results, we suggest that it is meaningful to attempt to identify differences in symptoms and gastric myoelectric activity according to the presence of an SCN5A mutation by EGG analysis. The relationship between FD and sodium channelopathy should be elucidated in the future by a large-scale study.

(J Neurogastroenterol Motil 2012;18:58-63)

Key Words

Brugada syndrome; Channelopathy; Functional gastrointestinal disorder; SCN5A

Received: October 20, 2011 Revised: December 14, 2011 Accepted: December 20, 2011

(c) This is an Open Access article distributed under the terms of the Creative Commons Attribution Non-Commercial License (http://creativecommons. org/licenses/by-nc/3.0) which permits unrestricted non-commercial use, distribution, and reproduction in any medium, provided the original work is properly cited.

*Correspondence: Hyojin Park, MD, PhD

Department of Internal Medicine, Gangnam Severance Hospital, Yonsei University College of Medicine, 712 Eonju-ro, Gangnam-gu, Seoul 135-720, Korea

Tel: +82-2-2019-3310, Fax: +82-2-3463-3882, E-mail: hjpark21@yuhs.ac

Financial support: This study was supported by a faculty research grant of the Department of Internal Medicine, Yonsei University, College of Conflicts of interest: None. Medicine, 2008 (Grant No. 7-2008-0422). 


\section{Introduction}

Functional dyspepsia (FD) is a common clinical syndrome consisting of recurrent or persistent abdominal symptoms of epigastric pain and fullness, early satiety, nausea, and/or vomiting in the absence of an organic cause. ${ }^{1,2}$ The pathophysiology of functional dyspepsia remains unclear, and many researchers have focused upon the following factors: gastric motor function, visceral sensitivity, Helicobacter pylori infection, and psychosocial factors. Among these, motility abnormalities of the stomach and upper small bowel have been found in the majority of patients with unexplained dyspepsia. ${ }^{2}$

Understanding on the control of gastrointestinal (GI) motility was greatly improved by the discovery that a specialized cell type, the interstitial cell of Cajal (ICC), is also required for coordinated motility. ${ }^{3-6}$ The ICC is an electrically active cell and generates the slow waves which play an important role in gastric motility. ${ }^{3,4}$ In ICC and intestinal smooth muscle cells, there are sodium channel $\alpha$-subunit gene ( $S C N 5 A$ ) encoded sodium channels as well as $\mathrm{KCNH2}$-encoded HERG potassium channels, which are associated with congenital long QT syndrome. It has been reported that there is no association between $K C N H 2$ genotype status and GI symptoms, whereas patients with mutations in SCN $5 A$ have a higher prevalence of GI symptoms. ${ }^{7}$
The sodium channel encoded by $S C N 5 A$ has been described in human intestinal ICC and smooth muscle cells. ${ }^{8-11}$ In these studies, it was revealed that sodium flux through the sodium channel regulates membrane potential and slow-wave frequency, suggesting that the channel may participate in the regulation of GI motility. $S C N 5 A$ also encodes the cardiac sodium channel responsible for the rapid depolarization of the cardiac action potential, and Brugada syndrome has been reported to be related to mutation of this gene (Figure). ${ }^{12}$

Therefore, we hypothesized that mutation of the SCN5A gene may lead to abnormalities of gastric myoelectrical activity in patients with Brugada syndrome. To test this hypothesis, we measured an electrogastrography (EGG) for detection of gastric myoelectrical activities and collected dyspeptic symptom questionnaires from patients with Brugada syndrome and functional dyspepsia. Additionally, we evaluated FD patients without Brugada syndrome in the same methods for comparison.

\section{Materials and Methods}

\section{Subjects and Clinical Data}

Patients with Brugada syndrome were recruited from the Yonsei Cardiovascular Genome Center from June 2008 to November 2010. Patients with FD were recruited from Gangnam

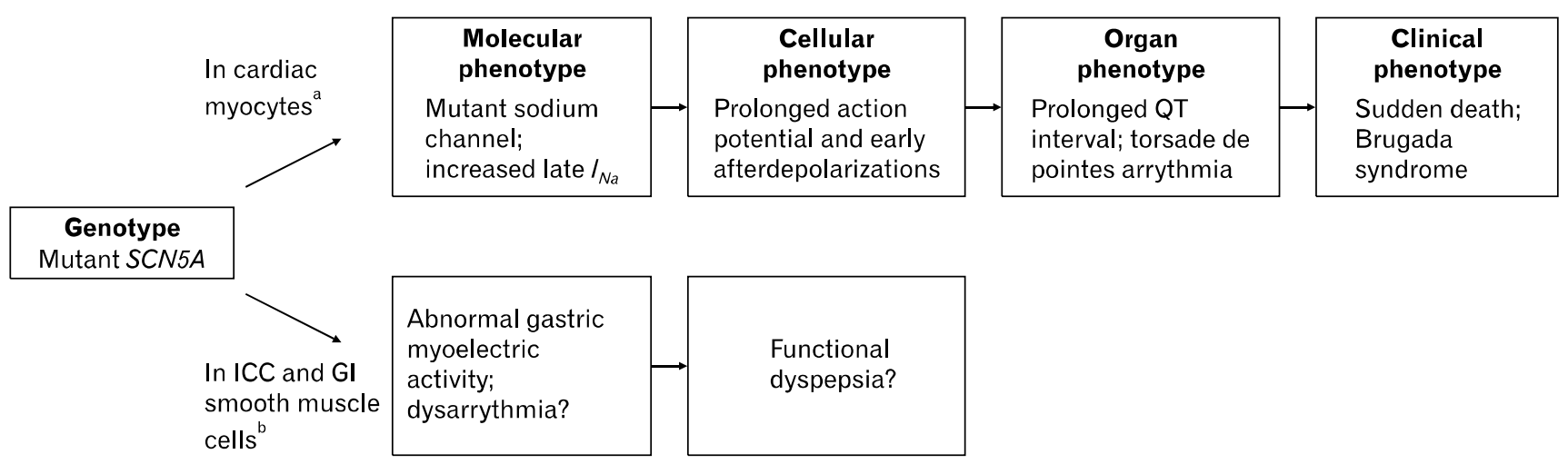

Figure. Arrhythmogenic pathogenetic pathway for Brugada syndrome and possible mechanism of functional dyspepsia (FD). ${ }^{a}$ The genetic abnormality in the cardiac sodium channel SCN5A causes a molecular phenotype of increased late sodium current which causes a cellular phenotype of prolonged action potential duration as well as early after depolarizations (Modified from Makielski ${ }^{13}$ ). Prolonged action potential in the cells of the ventricular myocardium produces tissue/organ phenotype of a prolonged QT interval on the electrocardiogram and torsade de pointes arrhythmia in the whole heart. If this is sustained or degenerates to ventricular fibrillation, the clinical phenotype of Brugada syndrome results. ${ }^{b}$ In interstitial cell of Cajal and gastrointestinal smooth muscle cells, sodium flux through the sodium channel regulates membrane potential and slow-wave frequency, suggesting that the channel may participate in the regulation of gastrointestinal motility. Therefore, mutation of the SCN5A gene may lead to abnormalities of gastric myoelectrical activity. Several reports suggest a close relationship between myoelectrical abnormalities and dyspeptic symptoms. Based on these information, our study was to present channelopathy as one of the pathophysiologic mechanism of FD. $I_{N a}$, sodium current; ICC, interstitial cell of Cajal; GI, Gastrointestinal. 
Severance Hospital over the same period. The protocol for this study was approved by Yonsei Medical Center Institutional Review Committee (3-2008-0066) in compliance with the Declaration of Helsinki, and the study was carried out under its guidelines. Informed consent was obtained from all participants.

The diagnosis of Brugada syndrome was based on a 12-lead ECG with the following ECG parameters: (1) at least a $2 \mathrm{~mm}$ ST-segment elevation in more than one right precordial lead (V1 to V3) with a right bundle branch block morphology and (2) a J-wave elevation $>0.2 \mathrm{mV}$ at baseline. The absence of a structural abnormality was confirmed by echocardiography. Patients confirmed Brugada syndrome received FD questionnaires, esphagogastoduodenoscopy, and genetic analysis of SCN5A from peripheral blood.

The diagnosis of FD was based on esophagogastroduodenoscopy and FD questionnaires. Participants diagnosed with FD were enrolled, and they were checked by ECG to exclude incidental co-morbidity of Brugada syndrome. Enrolled patients received EGG and genetic analysis of $S C N 5 A$ from peripheral blood.

\section{Questionnaires for Functional Dyspepsia}

FD was diagnosed according to Rome-III criteria. Symptoms of epigastric pain, epigastric burning, postprandial fullness, early satiety, postprandial bloating and postprandial nausea or excessive belching were scored in accordance with the following scheme: $0=$ none, $1=$ mild (symptom could be ignored if the patient did not think about it), 2 = moderate (symptom could not be ignored but did not influence daily activities) and $3=$ severe (symptom influenced daily activities). Symptom severity scores were added (minimum: zero to maximum 18). The frequency of dyspeptic symptoms described above was scored in accordance with the following scheme: $0=$ none, $1=$ once or twice in one month, $2=$ once or twice in one week and $3=$ above 3 times in a week. Scores were added (minimum: zero to maximum 18). Patients with FD were classified into 2 subtypes, PDS and EPS.

\section{Electrogastrography}

An ambulatory EGG (Digitrapper EGG, Synetics Medical Inc., Stockholm, Sweden) with active electrodes was used to record gastric myoelectrical activity. EGG was recorded in the morning after an overnight fast. To reduce the resistance between electrode and skin, conduction cream (Signa Creme ${ }^{\circledR}$, Parker Laboratories, Fairfield, NJ, USA) was applied to the skin after shaving the hair on the abdomen and performing abrasion with skin prepping paste $\left(\right.$ Omni Prep ${ }^{\circledR}$, DO Weaver \& Co., Aurora, $\mathrm{CO}$, USA). One active recording electrode was placed in the ventral midline halfway between the xiphoid process and umbilicus, a second active recoding electrode was placed $6 \mathrm{~cm}$ to the left of the first electrode, $45^{\circ}$ cephalad, and a third reference electrode was placed to the right of the first electrode. The 3 electrodes were connected to the Digitrapper EGG recording device. EGG of the preprandial period was recorded for 30 minutes before a meal, and EGG of the postprandial period was recorded for 30 minutes after a meal, with the patient in a sitting position, reclining at a $45^{\circ}$ angle in a comfortable chair. Solid meals (rice rolled up in dried seaweed with orange juice) were given to patients. All recording data were uploaded into a personal computer and analyzed by a software program (Polygram for Windows version 6.40, Synetics Medical Inc., Stockholm, Sweden).

EGG recording data were analyzed according to the following parameters: (1) percentage of normal gastric slow waves (approximately 2.0-4.0 cycle/min), bradygastria (1.8-2.0 cycle/ $\mathrm{min}$ ) and tachygastria (4.0-10.0 cycle/min); and (2) the ratio of postprandial to fasting dominant power.

\section{Genetic Analysis of SCN5A}

The mutation analysis was carried out by polymerase chain reaction (PCR) followed by direct sequencing. Genomic DNA was extracted from peripheral blood leukocytes using QIAamp ${ }^{\circledR}$ DNA blood kits (Qiagen, Valencia, CA, USA). The PCR was performed using modified primers to sites located in the intronic sequences and amplification conditions as previously described. ${ }^{14}$ The amplified products were purified using QIAquick ${ }^{\circledR}$ PCR purification kits (Qiagen) and directly sequenced using ABI PRISM Big Dye Terminator Cycle Sequencing Ready Reaction kits and an ABI PRISM 3730xl DNA analyzer (Applied Biosystems, Foster City, CA, USA). Sequences were compared with the reference genomic and cDNA sequences of SCN5A (GenBank accession numbers NT 022517.17 and AY148488.1, respectively) using BLASTN.

\section{Statistical Methods}

Questionnaire scores and parameters recorded by EGG were statistically analyzed by the Mann-Whitney U test and Fisher's exact test using SPSS 17.0. A $P$-value of less than 0.05 was considered significant. 
Table 1. Patient Characteristics and Symptom Scores

\section{Results}

\section{Patient Characteristics}

Four patients with Brugada syndrome were enrolled in this study (Table 1). Of 4 patients with Brugada syndrome, 3 were male and 1 was female. Their ages were between 29 and 59 years. SCN5A mutation was found in 3 patients (75\%), one of whom met diagnostic criteria for a postprandial distress syndrome (PDS) subtype of FD.

Thirteen patients with FD were enrolled (Table 1). Four were male and 9 were female. Their ages were between 20 and 69 years. Nine patients had a PDS subtype and 4 had a EPS subtype. SCN5A mutation was found in only 1 patient with a PDS subtype of FD (7.7\%).

Of 4 patients with $S C N 5 A$ mutation, $2(50 \%)$ had FD with a PDS subtype.

The severity and frequency of symptom scores are described in Table 1. Since number of patients was small, we could not find specific symptom patterns according to mutation of $S C N 5 A$ in

\begin{tabular}{|c|c|c|c|c|c|}
\hline \multirow{2}{*}{$\begin{array}{c}\text { Case } \\
\text { number }\end{array}$} & \multirow{2}{*}{ Age/Sex } & \multirow{2}{*}{$\begin{array}{l}S C N 5 A \\
\text { mutation }\end{array}$} & \multirow{2}{*}{$\begin{array}{l}\text { Subtype } \\
\text { of FD }\end{array}$} & \multicolumn{2}{|c|}{ Symptom score } \\
\hline & & & & Severity & Frequency \\
\hline \multicolumn{6}{|c|}{ Brugada syndrome } \\
\hline No. 1 & 29/M & + & PDS & 7 & 6 \\
\hline No. 2 & 49/M & + & - & 3 & 3 \\
\hline No. 3 & $58 / \mathrm{F}$ & + & - & 1 & 1 \\
\hline No. 4 & 49/M & - & EPS & 7 & 5 \\
\hline \multicolumn{6}{|c|}{ Functional dyspepsia } \\
\hline No. 5 & $58 / \mathrm{F}$ & + & PDS & 5 & 7 \\
\hline No. 6 & $23 / \mathrm{F}$ & - & PDS & 8 & 7 \\
\hline No. 7 & $37 / \mathrm{F}$ & - & PDS & 11 & 15 \\
\hline No. 8 & $31 / \mathrm{F}$ & - & PDS & 14 & 14 \\
\hline No. 9 & 20/M & - & PDS & 7 & 7 \\
\hline No. 10 & $37 / \mathrm{F}$ & - & PDS & 11 & 13 \\
\hline No. 11 & $20 / \mathrm{M}$ & - & PDS & 6 & 8 \\
\hline No. 12 & $69 / \mathrm{F}$ & - & EPS & 11 & 13 \\
\hline No. 13 & $26 / \mathrm{F}$ & - & EPS & 3 & 6 \\
\hline No. 14 & $53 / \mathrm{F}$ & - & EPS & 6 & 12 \\
\hline No. 15 & $70 / \mathrm{M}$ & - & PDS & 8 & 10 \\
\hline No. 16 & $36 / \mathrm{M}$ & - & PDS & 14 & 14 \\
\hline No. 17 & $49 / \mathrm{F}$ & - & EPS & 9 & 10 \\
\hline
\end{tabular}

FD, functional dyspepsia; PDS, postprandial distress syndrome; EPS, epigastric pain syndrome.

Table 2. Electrogastrographic Findings According to $S C N 5 A$ Mutation

\begin{tabular}{|c|c|c|c|c|c|c|c|}
\hline \multirow{2}{*}{ Case number } & \multirow{2}{*}{$\begin{array}{c}\text { Power ratio } \\
\text { (postprandial/preprandial) }\end{array}$} & \multicolumn{3}{|c|}{ Preprandial period $^{\mathrm{a}}$} & \multicolumn{3}{|c|}{ Postprandial period ${ }^{\mathrm{a}}$} \\
\hline & & Bradygastria & Normal & Tachygastria & Bradygastria & Normal & Tachygastria \\
\hline \multicolumn{8}{|c|}{$S C N 5 A$ mutation $(+)$} \\
\hline No. 1 & 1.0 & 9.1 & 90.9 & 0.0 & 75.0 & 0.0 & 25.0 \\
\hline No. 2 & 4.0 & 0.0 & 85.7 & 14.3 & 0.0 & 66.7 & 33.3 \\
\hline No. 3 & 0.4 & 15.8 & 84.2 & 0.0 & 6.7 & 60.0 & 33.3 \\
\hline No. 5 & 0.2 & 0.0 & 71.4 & 28.6 & 0.0 & 87.5 & 12.5 \\
\hline Mean \pm SD & $1.4 \pm 1.7$ & $6.2 \pm 7.7$ & $83.0 \pm 8.3$ & $10.7 \pm 13.7$ & $20.4 \pm 36.5$ & $53.5 \pm 37.6$ & $26.0 \pm 9.8$ \\
\hline \multicolumn{8}{|c|}{$S C N 5 A$ mutation (-) } \\
\hline No. 4 & 1.0 & 11.8 & 52.9 & 35.3 & 10.0 & 70.0 & 20.0 \\
\hline No. 6 & 0.4 & 0.0 & 100 & 0.0 & 8.3 & 75.0 & 16.7 \\
\hline No. 7 & 0.0 & 25.0 & 75.0 & 0.0 & 5.9 & 76.5 & 17.6 \\
\hline No. 8 & 0.6 & 62.5 & 25.0 & 12.5 & 57.1 & 42.9 & 0.0 \\
\hline No. 9 & N/A & 0.0 & 0.0 & 20.0 & 0.0 & 55.6 & 11.1 \\
\hline No. 10 & 0.9 & 25.0 & 25.0 & 50.0 & 7.7 & 69.2 & 23.1 \\
\hline No. 11 & 0.0 & 0.0 & 71.4 & 28.6 & 10.0 & 65.0 & 25.0 \\
\hline No. 12 & 1.3 & 23.5 & 35.3 & 41.2 & 6.7 & 93.3 & 0.0 \\
\hline No. 13 & 0.6 & 0.0 & 57.1 & 42.9 & 0.0 & 87.5 & 12.5 \\
\hline No. 14 & 1.4 & 41.7 & 58.3 & 0.0 & 0.0 & 50.0 & 50.0 \\
\hline No. 15 & 1.6 & 0.0 & 84.6 & 15.4 & 18.8 & 56.3 & 25.0 \\
\hline No. 16 & 2.1 & 20.0 & 60.0 & 20.0 & 0.0 & 100.0 & 0.0 \\
\hline No. 17 & 0.1 & 9.1 & 63.4 & 54.5 & 0.0 & 100.0 & 0.0 \\
\hline Mean $\pm \mathrm{SD}$ & $0.8 \pm 0.7$ & $16.8 \pm 19.1$ & $54.5 \pm 27.2$ & $24.6 \pm 19.1$ & $9.6 \pm 15.3$ & $72.4 \pm 18.7$ & $15.5 \pm 14.3$ \\
\hline
\end{tabular}

${ }^{a}$ Data are expressed as percentage.

$\mathrm{N} / \mathrm{A}$, not assessable. 
Table 3. Comparison of the Electrogastrographic Results Between the SCN5A Mutation Negative and Positive Groups

\begin{tabular}{|c|c|c|c|c|}
\hline & & \multicolumn{2}{|c|}{$S C N 5 A$} & \multirow{2}{*}{$P$-value } \\
\hline & & Mutation (-) $(\mathrm{n}=13)$ & Mutation $(+)(\mathrm{n}=4)$ & \\
\hline \multirow[t]{3}{*}{ Preprandial period } & Bradygastria & $2(15.4 \%)$ & $0(0.0 \%)$ & 0.120 \\
\hline & Normal & $5(38.4 \%)$ & $4(100.0 \%)$ & \\
\hline & Tachygastria & $6(46.2 \%)$ & $0(0.0 \%)$ & \\
\hline \multirow[t]{3}{*}{ Postprandial period } & Bradygastria & $2(15.4 \%)$ & $1(25.0 \%)$ & 0.099 \\
\hline & Normal & $10(76.9 \%)$ & $1(25.0 \%)$ & \\
\hline & Tachygastria & $1(7.7 \%)$ & $2(50.0 \%)$ & \\
\hline
\end{tabular}

patients with Brugada syndrome and FD.

\section{Electrogastrography Parameters}

The EGG results of each patient are described in Table 2. Four patients ( 3 Brugada syndrome and $1 \mathrm{FD}$ ) had SCN5A mutation in our study. Case 1 (No. 1) was a 29-year-old male who had Brugada syndrome associated with the PDS subgroup of FD. Power ratio $(\mathrm{PR})$ at $3 \mathrm{cycle} / \mathrm{min}$ was 1.0 . In the preprandial period, most of the frequency was in the normal range (90.9\%). However, in the postprandial period, the dominant frequency changed to bradygastria (75\%). Case 2 (No. 2) was a 49-year-old male with Brugada syndrome without GI symptoms. PR at 3 cy$\mathrm{cle} / \mathrm{min}$ was 4.0 , and $85.7 \%$ of the waves were in the $2-4 \mathrm{cy}-$ $\mathrm{cle} / \mathrm{min}$ range in the preprandial period. However, he had postprandial tachygastria (33.3\%). Case 3 (No. 3) was a 58-year-old female who has Brugada syndrome without FD, but PR at $3 \mathrm{cy-}$ $\mathrm{cle} / \mathrm{min}$ was decreased to 0.4 . She had normal slow waves (85.2\%) in the preprandial period, and tachygastria $(33.3 \%)$ in the postprandial period. Case 4 (No. 5) was a 58-year-old female who had a PDS subtype of FD without Brugada syndrome. PR at 3 cycle/min was decreased to 0.2 , but the dominant frequency was in the normal range in the pre-prandial $(71.4 \%)$ and post-prandial (87.5\%) periods, respectively.

Postprandial tachygastria and bradygastria were noted in 2 $(50 \%)$ and 1 (25\%) of 4 patients with SCN5A mutation, respectively.

In the SCN5A mutation negative group (12 FD and 1 Brugada syndrome), 2 patients were bradygastric (15.4\%), 5 patients were normal $(38.4 \%)$ and 6 patients were tachygastric $(46.2 \%)$ in the preprandial period. In addition, 2 patients were bradygastric (15.4\%), 10 patients were normal (76.9\%) and 1 patient was tachygastric $(7.7 \%)$ in the postprandial period. Seven patients (53.8\%) showed decreased postprandial PR.

However, the EGG parameters were not significantly different depending on SCN5A mutation (Table 3).

\section{Discussion}

The hypothesis of our study was that mutation in the $S C N 5 \mathrm{~A}$ gene may be related to dyspeptic symptoms and abnormalities of gastric myoelectrical activity in patients with Brugada syndrome and/or FD. Due to the limited number of patients in our study, we could not obtain significant differences in symptoms and/or EGG parameters depending on $S C N 5 A$ mutation.

$S C N 5 A$ encodes the molecular identity of the pore-forming a -subunit of the tetrodotoxin-insensitive sodium channel in both human intestinal smooth muscle and cardiac myocytes. ${ }^{11}$ The role of a sodium channel is less well defined in smooth muscle and ICC of the GI tract. There is a report, however, that a mechanosensitive sodium current present in human intestinal ICC may play an important role in the normal physiological control of human intestinal motor function by contributing to the setting of the membrane potential, the rate of rise of the slow wave, and mechanosensitive regulation of slow wave frequency. ${ }^{11}$ The electrical slow wave is generated from ICC. Blockers of the sodium current slow the rate of rise and decrease the frequency of the slow wave, while stretching of human circular smooth muscle strips for activation of the mechano-sensitive sodium channel which increases the frequency of the slow wave. ${ }^{11}$

Mutations in SCN5A that affect the electrical phenotype of the $\mathrm{Na}_{v} 1.5$ channel may therefore alter the contribution of the sodium channel to the intrinsic electrical activity of the intestine and may result in abnormal intestinal motility. ${ }^{7}$ In other words, GI phasic mechanical contractions are preceded by changes in the electrical activity of smooth muscle cells.

It is a well-known fact that mutations in the $S C N 5 A$ gene have been linked to a variety of diseases causing sudden cardiac death in cardiology. The sodium channel isoform Nav1.5, encoded by the $S C N 5 A$ gene, is the predominant a-subunit in the heart, and plays a key role in the excitability of atrial and ventricular cardiomyocytes. Mutations in SCN5A that result in de- 
fined electrophysiological abnormalities can be divided into 2 primary arrhythmogenic phenotypes in the heart. ${ }^{15}$ One is gain-offunction mutations to yield the LQT3 phenotype, ${ }^{16}$ and the other is loss-of-function mutations resulting in the $\mathrm{BrS} 1$ phenotype. ${ }^{17}$

One study reported that there is the possibility that both gainand loss-of-function mutations involving the sodium channel may increase susceptibility to GI symptoms.

They showed that subjects with an SCN5A mutation had more GI symptom complexes (OR 5.2; 95\% CI, 1.5-18.3). ${ }^{7}$ There is also a study that evaluated $S C N 5 A$ as a candidate gene involved in the pathogenesis of irritable bowel syndrome (IBS). ${ }^{18}$ These researchers recruited 49 subjects diagnosed with IBS and performed mutational analysis on their genomic DNA. They found that the G298S-SCN5A missense mutation caused a marked reduction of whole cell sodium current and loss of function of Nav1.5, and suggested the concept of an intestinal channelopathy resulting in IBS. However, we did not find specific symptom patterns according to mutation of $S C N 5 A$ in patients with Brugada syndrome and FD.

There are several reports that suggest a close relationship between dyspeptic symptoms and myoelectrical abnormalities including instability of the gastric pacemaker frequency, tachygastria in both the fasting and postprandial states, or the absence of the normal amplitude increase in the postprandial period. ${ }^{19,20}$ Therefore, we attempted to prove the possible relationship between SCN5A mutation and gut channelopathy by EGG analysis.

A limitation of our study is that the number of subjects was too small. Although our institution is a tertiary referral center, there were only a few dozen people who could participate in this study because of the extremely low prevalence of Brugada syndrome.

Although we did not find statistically significant results both in symptoms and EGG parameters, it is meaningful to attempt to identify differences in gastric myoelectric activity according to the presence of SCN5A mutation. In order to demonstrate channelopathy as one of the pathophysiologic mechanism of FD, a large-scale multi-center study is needed in the future.

\section{References}

1. Locke GR, Talley NJ. Management of non-ulcer dyspepsia. J Gastroenterol Hepatol 1993;8:279-286.

2. Babara L, Camilleri M, Corinaldesi R, et al. Definition and investigation of dyspepsia: consensus of an international ad hoc working party. Dig Dis Sci 1989;34:1272-1276.

3. Ward SM, Burns AJ, Torihashi S, Sanders KM. Mutation of the proto-oncogene c-kit blocks development of interstitial cells and electrical rhythmicity in murine intestine. J Physiol 1994;480(Pt 1): 91-97.

4. Huizinga JD, Thuneberg L, Klüppel M, Malysz J, Mikkelsen HB, Bernstein A. W/kit gene required for interstitial cells of Cajal and for intestinal pacemaker activity. Nature 1995;373:347-349.

5. Beckett EA, Horiguchi K, Khoyi M, Sanders KM, Ward SM. Loss of enteric motor neurotransmission in the gastric fundus of $\mathrm{Sl} / \mathrm{Sl}(\mathrm{d})$ mice. J Physiol 2002;543:871-887.

6. Ward SM, Beckett EA, Wang X, Baker F, Khoyi M, Sanders KM Interstitial cells of Cajal mediate cholinergic neurotransmission from enteric motor neurons. J Neurosci 2000;20:1393-1403.

7. Locke GR 3rd, Ackerman MJ, Zinmeister AR, Thapa P, Farrugia G. Gastrointestinal symptoms in families of patients with an SCN5A-encoded cardiac channelopathy: evidence of an intestinal channelopathy. Am J Gastroenterol 2006;101:1299-1304.

8. Ou Y, Strege P, Miller SM, et al. Syntrophin gamma 2 regulates $S C N 5 A$ gating by a PDZ domain-mediated interaction. J Biol Chem 2003;278:1915-1923.

9. Strege PR, Holm AN, Rich A, et al. Cytoskeletal modulation of sodium current in human jejunal circular smooth muscle cells. Am J Physiol Cell Physiol 2003;284:C60-C66.

10. Ou Y, Gibbons SJ, Miller SM, et al. SCN5A is expressed in human jejunal circular smooth muscle cells. Neurogastroenterol Motil 2002;14:477-486.

11. Strege $\mathrm{PR}, \mathrm{Ou} \mathrm{Y}$, Sha $\mathrm{L}$, et al. Sodium current in human intestinal interstitial cells of Cajal. Am J Physiol Gastrointest Liver Physiol 2003;285:G1111-G1121.

12. Chen Q, Kirsch GE, Zhang D, et al. Genetic basis and molecular mechanism for idiopathic ventricular fibrillation. Nature 1998;392: 293-296.

13. Makielski JC. SIDS: genetic and environmental influences may cause arrhythmia in this silent killer. J Clin Invest 2006;116:297-299.

14. Wang Q, Li Z, Shen J, Keating MT. Genomic organization of the human $S C N 5 A$ gene encoding the cardiac sodium channel. Genomics 1996;34:9-16.

15. Zimmer T, Surber R. SCN5A channelopathies - an update on mutations and mechanisms. Prog Biophys Mol Biol 2008;98:120-136.

16. Wang Q, Shen J, Splawski I, et al. SCN5A mutations associated with an inherited cardiac arrhythmia, long QT syndrome. Cell 1995;80: 805-811.

17. Roden DM, Balser JR, George AL Jr, Anderson ME. Cardiac ion channels. Annu Rev Physiol 2002;64:431-475.

18. Saito YA, Strege PR, Tester DJ, et al. Sodium channel mutation in irritable bowel syndrome: evidence for an ion channelopathy. Am J Physiol Gastrointest Liver Physiol 2009;296:G211-G218.

19. Geldof H, van der Schee EJ, van Blankenstein M, Grashuis JL. Electrogastrographic study of gastric myoelectrical activity in patients with unexplained nausea and vomiting. Gut 1986;27:799-808.

20. Chen JZ, McCallum RW. Electrogastrography. New York: Raven 1994. 